\title{
Caracterización y desarrollo del "saber luchar": contenidos de un modelo integrado para la enseñanza de las artes marciales y de los deportes de combate
}

\author{
Bruno AVELAR-ROSA ${ }^{1 *}$, Mariana Simões Pimentel GOMES², Abel FIGUEIREDO³ ${ }^{3}$ \& Víctor \\ LÓPEZ-ROS 4 \\ ${ }^{1}$ Instituto Politécnico de Viseu (Portugal) / Universitad de Girona (España) \\ 2 Universidade Estadual de Campinas (Brasil) \\ 3 Instituto Politécnico de Viseu (Portugal) \\ ${ }^{4}$ Cátedra de Deporte y Educación Física - Centro de Estudios Olímpicos. Universidad de Girona (España)
}

Recepción: 16/01/2015; Aceptación: 19/06/2015; Publicación: 24/06/2015.

\section{Resumen}

ORIGINAL PAPER

El objetivo de este trabajo es definir los principios y contenidos técnico-tácticos que caracterizan el "saber luchar" en el ámbito de las artes marciales y deportes de combate entendidos en su sentido global. Desde el punto de vista metodológico, buscamos detectar los límites práxicos del conjunto de las diferentes disciplinas de las artes marciales y deportes de combate a través del análisis de puntos de convergencia que puedan conferirles consistencia como grupo de prácticas, y a partir de los cuales resulte posible desarrollar un proceso de enseñanza-aprendizaje coherente. Los principios y contenidos que consideramos desde esta perspectiva integrada establecen las posibilidades de acción independientemente de los condicionantes técnicos institucionalizados por las diferentes modalidades de combate. Sobre la base de la "estructura técnico-táctica del saber luchar", se propone desarrollar el "saber luchar" enfatizando la importancia de incidir sobre la "intención táctica" de los aprendices. La distribución y categorización de las acciones luctatorias que presentamos busca ofrecer herramientas y criterios para ayudar en el proceso de iniciación a las artes marciales y deportes de combate.

Palabras clave: Artes marciales; deportes de combate; saber luchar; enseñanza-aprendizaje.

"Fighting knowledge" characterization and development: contents of an integrated model for teaching martial arts and combat sports

\section{Abstract}

This paper aims to define the principles and technicaltactical contents that characterize the global "fighting knowledge" referring to martial arts and combat sports. From a methodological point of view, we seek to identify the praxical limits of the different martial arts and combat sports disciplines, through the analysis of the convergence points, which can provide consistency as a group of practices, and from where is possible to develop a teaching process. The principles and contents considered in this integrated perspective establish the possibilities of action, independently from institutionalized technical abilities in each combat sport. From the "fighting knowledge technical-tactical structure" we propose the development of the "fighting knowledge" and we emphasize the importance of arising the "tactical intention" of the students. The distribution and categorization of the "fighting actions" presented, try to offer tools and criteria for the martial arts and combat sports initiation process.

Keywords: Martial arts; combat sports; fighting knowledge, teaching-learning.
Caraterização e desenvolvimento do "saber lutar": conteúdos de um modelo integrado para o ensino das artes marciais e dos desportos de combate

\section{Resumo}

O objetivo deste trabalho é definir os princípios e conteúdos técnico-táticos que caraterizam o "saber lutar" no âmbito das artes marciais e desportos de combate entendidos no seu sentido global. Do ponto de vista metodológico, procuramos detetar os limites práxicos do conjunto das diferentes disciplinas das artes marciais e desportos de combate através da análise de pontos de convergência que lhes possam conferir consistência enquanto grupo de práticas e a partir dos quais se torna possível desenvolver um processo de ensino-aprendizagem coerente. Os princípios e conteúdos que consideramos nesta perspetiva integrada estabelecem as possibilidades de ação independentemente das condicionantes técnicas institucionalizadas pelas diferentes modalidades de combate. A partir da "estrutura técnicotática do saber lutar" é proposto o desenvolvimento do "saber lutar" enfatizando a importância de incidir sobre a "intenção tática" dos aprendizes. A distribuição e categorização das ações lutatórias que apresentamos procura oferecer ferramentas e critérios para ajudar no processo de iniciação às artes marciais e desportos de combate.

Palavras-chave: Artes marciais; desportos de combate; saber lutar; ensino-aprendizagem.

\footnotetext{
* E-mail: bruno.ibe@gmail.com. Dirección: Departamento de Ciências do Desporto e Motricidade. Escola Superior de Educação - Instituto Politécnico de Viseu. Rua Maximiano Aragão. 3405-501 Viseu (Portugal).
} 


\section{Introducción}

La perspectiva vinculada al análisis y desarrollo de los procesos de enseñanza-aprendizaje es una de las líneas de investigación en el ámbito de las artes marciales y deportes de combate ${ }^{1}$ $(A M \& D C)$ que ha experimentado una mayor proliferación de trabajos durante las últimas décadas (e.g., Gutiérrez-García \& Pérez-Gutiérrez, 2009; Pérez-Gutiérrez, 2012). En concreto, la enseñanza mediante modelos eclécticos y globales ha sido objeto de reflexión y desarrollo desde la segunda mitad de los años 80 (Terrisse, 1996; Espartero, Gutiérrez-García, \& Villamón, 2003). En este sentido, "son numerosos los autores que, partiendo de una iniciación genérica y multidisciplinar, han postulado a favor de una iniciación polideportiva en la que se adquieran y perfeccionen las habilidades propias de las actividades de lucha" (Espartero, Gutiérrez-García, \& Villamón, 2003, p. 301).

Efectivamente, desde nuestro punto de vista, iniciar la formación en AM\&DC no significa “iniciarse en 'Lucha', 'Judo', 'Boxeo', 'Esgrima', 'Kárate', etc." (Figueiredo, 1998, p. I) ${ }^{2}$ consideradas como iniciaciones propias, específicas y diferenciadas para cada disciplina, sino que implica favorecer las situaciones de juego y de confrontación dual que caracterizan a todas estas modalidades. Esta perspectiva global "apunta hacia una formación ecléctica, donde los contenidos y materias deben estar sujetos a las exigencias del éxito del proceso de enseñanza-aprendizaje, debiendo los Deportes de Combate ser considerados de manera integrada" (Lima, 1997, p. 19). Asimismo, no se trata de proponer una perspectiva ecléctica de las AM\&DC que incluya el tratamiento parcializado, aunque sumado, de sus diferentes modalidades. Más bien, lo que se propone es analizar y tomar en consideración los contenidos transversales y comunes que en su conjunto caracterizan lo que Figueiredo (2006) designa como motricidad de combate. Estos contenidos son convergentes en las diferentes especialidades técnicas que podemos encontrar en este grupo de prácticas. De esta manera, y según Nascimento (2014, p. 175),

se deja de considerar la lucha como una categoría clasificatoria que contiene las diferentes formas específicas de combate, para, por el contrario, comprender su 'lógica o dinámica interna' o su 'problemática común', la cual condiciona la existencia de cada una de las modalidades o manifestaciones específicas.

Tal como señala Parlebas (2001, p. 302) la lógica interna representa el "sistema de rasgos pertinentes de una situación motriz y de las consecuencias que entraña para la realización de la acción motriz correspondiente". Algunos de los elementos distintivos de la lógica interna de una determinada situación motriz están vinculados con las formas de relación con los demás o con los roles y subroles ${ }^{3}$ que esa relación promueve en cada uno de los participantes a lo largo de su proceso de interacción. Esta perspectiva rompe con las propuestas de clasificación más difundidas (e.g. agrupando las prácticas en AM\&DC de golpeo o AM\&DC de agarre), que caracterizan los distintos grupos a partir de sus diferencias y no de los principios que determinan su lógica interna común (Gomes, et al., 2010).

En coherencia con la perspectiva horizontal de las AM\&DC que proponemos - entendiendo el término horizontal como la "enseñanza común a varios juegos deportivos apoyados sobre la base

\footnotetext{
1 Pérez-Gutiérrez, Gutiérrez-García, y Escobar-Molina (2011) señalan que en las publicaciones internacionales dedicadas a las luchas, artes marciales, deportes de combate y otras manifestaciones y terminologías cercanas, prevalece la designación de artes marciales y/o deportes de combate para denominar los mismos ámbitos de práctica. Por ello, aquí utilizamos el término "artes marciales y deportes de combate" (AM\&DC) recomendado por estos autores.

2 Las citas de Figueiredo (1997, 1998, 2003), Lima (1995, 1997), Nascimento (2014), Gomes (2014) Gomes, et al. (2010), Terrisse, et al. (1995), Lowry (2002) y Light (2014) son traducciones de los autores a partir de los originales en portugués, francés e inglés.

3 Asociados a los aspectos funcionales de los juegos, los roles y subroles representan las unidades de acción motriz (Parlebas, 1988). Parlebas (2001, p. 399) define el rol como el "conjunto de comportamientos motores que en un juego deportivo están asociadas a un estatus sociomotor concreto". El rol representa así el papel asumido por un jugador y las funciones, decisiones y acciones motoras que le caracterizan y diferencian. De forma complementar, el subrol consiste en la "secuencia ludomotriz de un jugador considerada como unidad comportamental básica para el funcionamiento estratégico de un juego deportivo" (Parlebas, 2001, p. 430). De esta manera, el subrol se asume como la unidad mínima de interacción del jugador representando "cada una de las posibles conductas de decisión que el jugador puede asumir y realizar durante el desarrollo del juego" (Hernández Moreno, 1995, p. 296).
} 
de estructuras comunes y similitudes tácticas entre ellos" (Devís \& Sánchez, 1996, p. 169 - distintos trabajos (Terrisse, 1991, 1996; Terrisse, et al., 1995) sugieren la existencia de un conocimiento inherente a la dialéctica de combate, independientemente de su contexto específico de aplicación. Este conocimiento, denominado "saber luchar", tendría un carácter fundamentalmente procedimental y genérico, y se manifestaría en la acción luctatoria a través de la llamada "intención táctica"4. Para Avelar y Figueiredo (2009, p. 46) este concepto debe entenderse como "aquella capacidad que permite al deportista solucionar las diversas situaciones que suceden durante un combate, independientemente de los modelos técnicos de ejecución que caracterizan las diferentes modalidades y cuyo reconocimiento institucional impone determinadas reglas". Asimismo el concepto de "intención táctica", a diferencia de la acción táctica individual entendida exclusivamente como la toma de decisiones en función del contexto, implica la noción de pensamiento o conciencia táctica (que establece la pertinencia y adecuación de las decisiones que se toman).

De esta forma, el "saber luchar" deberá expresarse a través de la demostración intencional de "la capacidad de tener un rol o de pasar de uno al otro" (Terrisse, et al., 1995, p. 27), consistiendo por ello "en la apropiación de la intención táctica para garantizar así las adaptaciones a la dinámica y a la lógica interna de los combates" (Gomes, 2014, p. 38). Sin embargo, más allá de las referencias de los autores mencionados y de nuestra convicción en el interés de este concepto, queda todavía por aclarar su posible concreción en el contexto de práctica. Como mantiene Nascimento (2014), existe una gran diferencia entre las características y las definiciones que se proponen para la actividad de lucha y el análisis de tales características en relación con su proceso de desarrollo.

En este sentido, un primer aspecto importante es definir qué principios y qué conocimientos técnicos y tácticos deberían constituir el "saber luchar" si entendemos que dicho saber es el desempeño integrado técnico-táctico de las habilidades luctatorias, independientemente de su orientación, disciplina, y de las particularidades individuales del enseñante y del aprendiz. Asimismo, es necesario establecer en un futuro las particularidades y características propias de este "saber" en tanto que tipo de conocimiento. Desde nuestro punto de vista es esencialmente un saber práctico y, por tanto, procedimental. Sin embargo se aleja de la llamada racionalidad técnica para asentarse en el marco de una racionalidad práctica comprensiva basada en la interacción entre el estricto procedimiento práctico y el conocimiento conceptual que lo enriquece y le aporta sentido.

En este trabajo, y de acuerdo con lo indicado anteriormente, pretendemos en primer lugar mostrar cuáles son los principios y contenidos de enseñanza-aprendizaje transversales a las diferentes AM\&DC, para luego poder definir qué directrices metodológicas y didácticas pueden tomarse en consideración para facilitar su aprendizaje. Para ello es preciso definir y sistematizar los contenidos que constituyen las AM\&DC. El análisis de la organización interna y de los rasgos específicos que les caracteriza deberá servir de base al planteamiento de un proceso de iniciación y desarrollo de estas prácticas bajo un modelo horizontal que promueva la futura transferencia de los contenidos en las diferentes AM\&DC.

\section{Metodología}

El proceso metodológico seguido para la realización del presente estudio parte de la revisión de las aportaciones que distintos autores han realizado a los modelos eclécticos y globales

\footnotetext{
${ }^{4}$ La designación original de los autores se refiere a una "intención estratégica". Sin embargo, debido al concepto que los autores expresan bajo esta denominación, Avelar y Figueiredo (2009, p. 54) consideran ser "más adecuado hablar de táctica (cómo solucionar los problemas observados durante el combate) que de estrategia (la cual se refiere al planteamiento previo de la dinámica del combate)". Esta perspectiva es coincidente con la de Sánchez (2009, p. 95) cuando señala que "la estrategia implica un distanciamiento de la actividad, un análisis previo al juego (por ejemplo mediante el visionado de los rivales, la preparación de jugadas) y es la función principal propia de un actor que no es jugador pero que está en íntima relación con ellos: la figura del entrenador". Asimismo, la estrategia implica "las normas de funcionamiento establecidas antes de la práctica motriz" (López-Ros \& Castejón, 1998, p. 6). Por otro lado, Sánchez (2009, p. 96) refiere también que la táctica "sirve para ayudar a la intencionalidad consciente en la adaptación a la situación. Tener unos buenos fundamentos tácticos es ser capaz de discriminar las jugadas buenas y las malas, las jugadas siquiera posibles o las que no tienen ni sentido".
} 
de enseñanza de las AM\&DC desde finales de la década de 1980. Estas aportaciones se han analizado y también se han revisado bases de datos como Sportdiscus, b-On, Dialnet o Scielo para encontrar otras referencias. Con todo, este trabajo no es una revisión, y por tanto no pretende ser exhaustivo y considerar todas las aportaciones realizadas en las últimas décadas, sino únicamente aquellas que se han apreciado como más relevantes atendiendo a sus fines. En este sentido, son destacables las aportaciones de autores franceses, españoles, portugueses y brasileños. En la construcción de la propuesta que presentamos, como ya ha podido apreciarse, la praxiología motriz ocupa un papel destacado como marco interpretativo de la dinámica de lucha. Asimismo, también reconocemos influencias de los modelos de enseñanza comprensiva del deporte, particularmente a través de la discusión de los aspectos tácticos e intencionales de la dinámica luctatoria. Para su mejor comprensión, el trabajo se ha estructurado en tres partes fundamentales. En la primera se debate la lógica interna que caracteriza este grupo de prácticas, y las dos siguientes están dedicadas al análisis de las acciones con carácter técnico y de los elementos de gestión táctica, cuya manipulación estimula el desarrollo integrado de la "intención táctica", y que de forma integrada constituyen lo que entendemos como el cuerpo de conocimientos del "saber luchar".

\section{Hacía una caracterización del "saber luchar"}

Desde una perspectiva praxiológica de análisis de las AM\&DC, Castarlenas (1993, p. 61) señala la existencia de tres roles en la acción luctatoria, los cuales "pueden ir cambiando de una forma constante y con grande rapidez" (Figura 1).

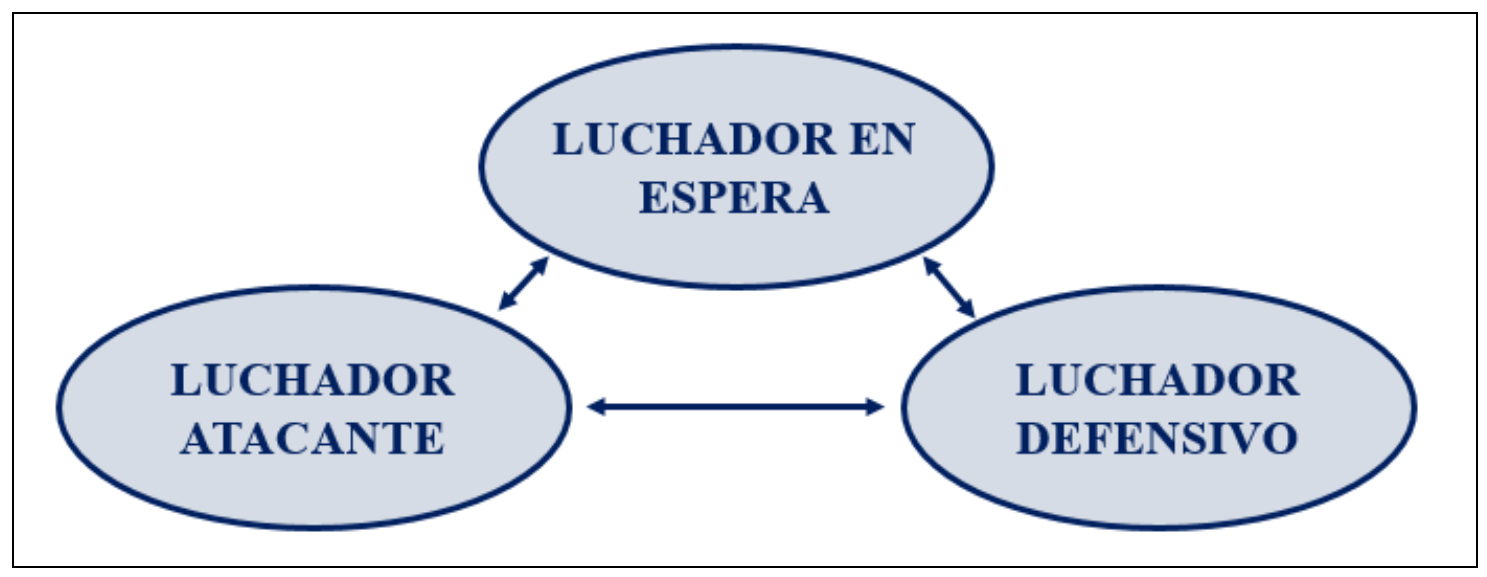

Figura 1. Estructura de cambio de roles, según Castarlenas (1993, p. 61).

Castarlenas (1993) reconoce la existencia de un rol en el cual el practicante se encuentra "en espera", considerándose este como previo o intermedio - decisorio - de los roles ofensivo o defensivo. En la misma lógica, Amador (1997) refuerza la perspectiva polarizada de la dinámica luctatoria al afirmar que en las AM\&DC las situaciones de ataque y de defensa son excluyentes entre sí puesto que son opuestas y antagónicas, lo que significa que siempre que un contrincante ataca, el otro necesariamente defiende.

En sentido contrario, Gomes, et al. (2010, p. 214) reconocen la "fusión ataque/defensa" como uno de los "principios condicionales de las luchas", señalando que:

tales acciones son simultáneas y hasta cierto punto fusionadas, ya que es raro observarlas aisladamente, sea en la interacción entre los sujetos (en algunos momentos es difícil saber si los

\footnotetext{
${ }^{5}$ Estos autores definen los “principios condicionales de las luchas” inspirados en los "principios operacionales” propuestos por Bayer (1986) en referencia a los JDC, aplicándolos de acuerdo con las particularidades de las AM\&DC. De esta forma, son considerados, además de la mencionada "fusión ataque/defensa", la “imprevisibilidad”, el "contacto intencional”, el "oponente/diana” - o como afirma Figueiredo (1997, p. 37), “el cuerpo del otro es objeto y objetivo de juego" - y las "reglas” definidoras de las diferentes manifestaciones luctatorias más o menos institucionalizadas.
} 
luchadores están realizando acciones ofensivas o defensivas) o en las acciones de uno de los luchadores (que puede defender con la pierna y atacar con los miembros superiores concomitantemente, por ejemplo).

Este concepto de "fusión ataque/defensa" es coherente con las aportaciones de otros autores. Así, Figueiredo (2003) destaca la "guardia"6 como la posición (y actitud) que representa y potencia a la vez el ataque y la defensa. Por su parte Terrisse (1991) señala la necesidad de tomar en consideración la transición en el ámbito del comportamiento dual que ocurre a lo largo del combate. Asimismo, la guardia representa la fusión permanente de los procesos ofensivo y defensivo indicada por Gomes, et al. (2010), la cual "posibilita a los luchadores, como acción general, dificultar la relación del oponente con su diana (mi cuerpo como blanco) y facilitar la relación de ataque con la diana de la lucha (el cuerpo del adversario como blanco)" (Nascimento, 2014, p. 183).

Efectivamente, la guardia, a través de sus manifestaciones de expansión o contracción, estimula a la vez la atención selectiva de índole ofensiva (búsqueda y selección del momento oportuno para el ataque) y la de índole defensiva (y contraofensiva). En esta línea podemos observar que una determinada guardia puede indicar la existencia de un proceso más ofensivo, así como, simultáneamente, una actitud luctatoria de expectativa que se manifiesta a través de la apertura de áreas con mayor potencial de acción, invitando al oponente a atacarlas. En este sentido, la guardia se asume como el centro de las acciones luctatorias representando la existencia y desarrollo de un proceso de transición (y no solamente de "espera") que, además de intermediario de las acciones con carácter ofensivo y defensivo (y constituyente de ambas), también se revela temporal y tácticamente prevalente respecto a estos procesos. Esta percepción de la dinámica luctatoria encuentra soporte en uno de los ejes de acción propuestos por Terrisse (1991, p. 11) ${ }^{7}$ - la contradicción "atacar-defender", cuyo significado el autor explicita afirmando que:

todo ataque contiene, en efecto, los elementos de su fracaso pues exige una apertura de la guardia o la creación de un desequilibrio consecutivo a un desplazamiento. La guardia pierde su función de preservación de la neutralidad en la medida en que condiciona a la vez tanto el ataque como la defensa. Su apertura es una condición previa a toda ofensiva pero contiene al mismo tiempo los gérmenes de la contra y, entonces, su propia negación.

Un aspecto destacado de la contradicción "atacar-defender" propuesta por Terrisse (1994), y al revés de la interpretación de Castarlenas (1993) y Amador (1997) al respecto de la lógica interna de las AM\&DC, está relacionado con el hecho de que la alternancia de roles entre los oponentes no resulta fácil de identificar porque en realidad la acción puede no ser única o exclusiva y por tanto, resulta no dicotómica. La doble funcionalidad de la guardia implica que cada oponente pueda ser atacante y defensor al mismo tiempo.

En las AM\&DC, los procesos ofensivos y defensivos no solamente coexisten potencialmente en cada uno de los oponentes, de forma permanente, sino que también cada uno de los contrincantes representa para el otro una potencial diana (en diferentes áreas corporales), a la vez que se asumen como el origen potencial de una acción de ataque. De este modo, el combate evoluciona en una lógica de transición dual sobre la cual la posible intencionalidad ofensiva de la guardia de uno de los oponentes potenciará la ruptura de este equilibrio dialéctico a través de la ejecución de una o más acciones de finalización (y, en consecuencia, el eventual recurso a las acciones de neutralización por parte del otro, intentando así evitar el éxito del oponente que ataca y la realización de una acción de contraataque o de anticipación). En caso de fracaso ofensivo, y

\footnotetext{
${ }^{6}$ Desde nuestro punto de vista, la "guardia”, designada por Figueiredo (2003) como la "posición base fundamental” o "posición fundamental de transición”, considera la postura y actitud de control defensivo y ofensivo del combate por parte de los oponentes. De esta manera, la guardia puede representarse, a corta o media distancia y con contacto intermitente, por la elevación de los puños ante el pecho (típico de las situaciones de golpeo) o, en la distancia nula con contacto permanente, el agarre del oponente sea en pie o en el suelo (típico de las situaciones de agarre).

${ }^{7}$ Este artículo fue publicado primero en francés en 1991 y luego traducido al castellano en 1994. Por una cuestión idiomática utilizaremos las referencias a la versión castellana.
} 
también contraofensivo, se restablece la dialéctica de transición dual, tal como aparece expresado en la Figura 2.

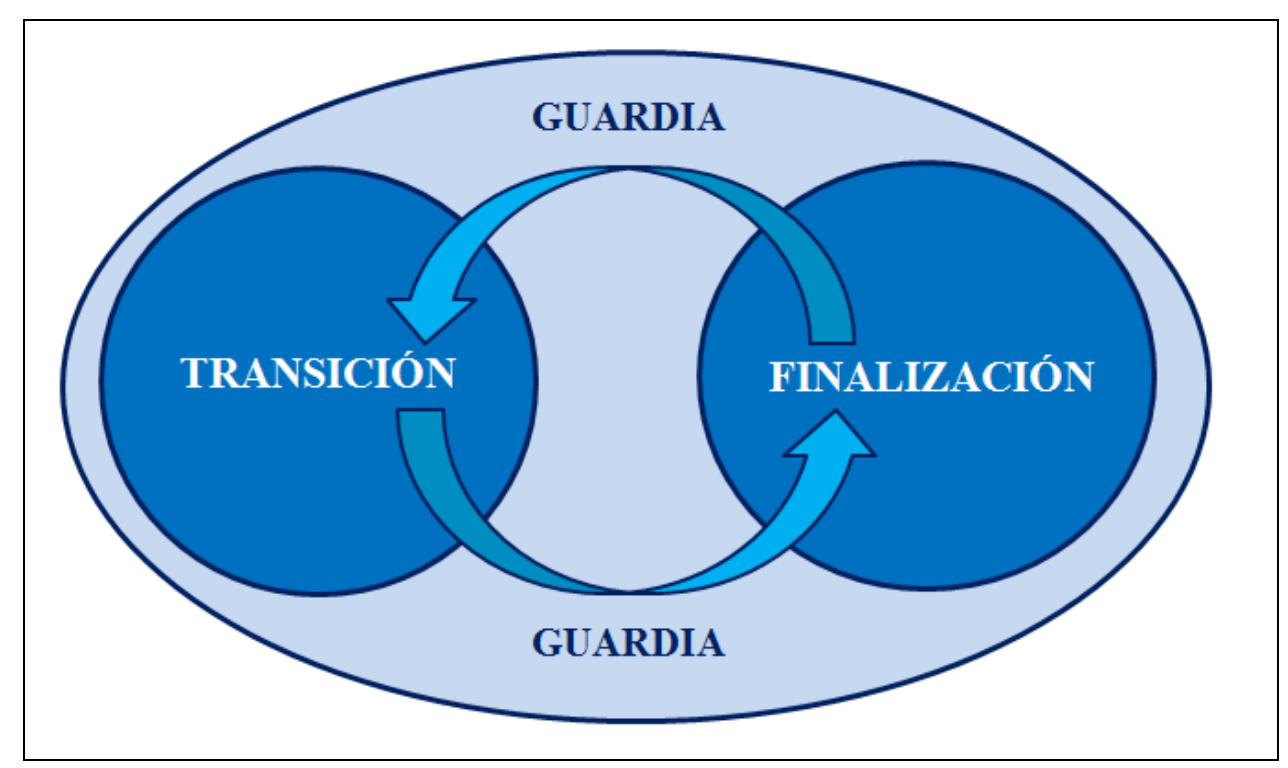

Figura 2. Representación de la dinámica de combate - La guardia como centro potenciador de la acción (fuente: elaboración propia).

El equilibrio dialéctico característico y determinante del proceso de transición solo se rompe cuando ocurre una acción finalizadora por parte de uno de los oponentes, la cual puede potenciar la acción del otro para la neutralización y contrafinalización o para la anticipación con finalización. Esta acción finalizadora, puede representar no solamente el éxito del atacante sino también, al revés, su fracaso. Asimismo, tal como supone Terrisse (1994, p. 11), la dinámica de los procesos ofensivos y/o defensivos "no pasa por una elección previa de los papeles (atacantedefensor), sino por un juego dialéctico entre los dos en función de la situación".

Desde nuestro punto de vista, entender esta lógica particular de las AM\&DC, basada en la relación de dependencia establecida entre la guardia, las acciones de transición (con carácter exploratorio, manipulativo y disuasorio) y las ejecuciones con carácter ofensivo/contraofensivo (acciones de finalización/neutralización), se revela fundamental para la identificación y organización de los conocimientos técnicos y tácticos inherentes al desarrollo del "saber luchar".

De forma complementaria, consideramos que las acciones de finalización representan el principio del "contacto intencional" propuesto por Gomes, et al. (2010, p. 213). Este principio,

puede ocurrir de diferentes maneras (a través de las manos, los brazos, las piernas, de todo el cuerpo o mediado por un implemento; continua o ininterrumpidamente) y debe acontecer para que haya Lucha y para que esta se desarrolle. Este principio condicional exige que los oponentes se toquen (intención/propósito) de alguna forma (técnico-táctica) para conquistar el objetivo de la lucha y obtener éxito sobre los adversarios.

De acuerdo con lo expuesto, para que la finalización pueda ocurrir, es inevitable el establecimiento intencional de contacto corporal buscando cada contrincante las formas más ventajosas de hacerlo (Nascimento, 2014).

Desde nuestro punto de vista, la dinámica asociada al proceso de transición, cuyo objetivo es encontrar o provocar la situación o momento oportuno para lograr el contacto exitoso, encuentra su reflejo en los presupuestos de la "intención táctica" considerada por Terrisse, et al. (1995), ya que su dominio determina la capacidad prospectiva y decisoria, demostradas a través de la búsqueda, el reconocimiento y el aprovechamiento de indicadores que suscitan la realización de las acciones. De esta forma, la pericia luctatoria también ocurre durante el proceso de transición y no solamente a través de la ejecución de las acciones de finalización. 
De acuerdo con lo expuesto, las dimensiones técnica y táctica representan dos facetas dependientes y concomitantes del comportamiento luctatorio, correspondiendo a cada una de ellas diferentes elementos de análisis y gestión que están en permanente relación. Por un lado, la dimensión técnica integra la realización de los gestos técnicos (las situaciones características del combate, tal como veremos más adelante), relacionando aquellos que son potencialmente puntuables (acciones de finalización) con los que no lo son (acciones de transición) pero que, en su articulación, promueven la ejecución de los anteriores. Por otro lado, la dimensión táctica implica la toma de decisiones en función de la variedad, calidad e intencionalidad de los aspectos inherentes a la acción transitiva. Es decir, la percepción de las dianas, ritmos y oportunidades, con el objetivo de reducir la "imprevisibilidad"8 del duelo. Si bien el presente trabajo no fija su atención en las particularidades de la dinámica evolutiva de las situaciones luctatorias, la noción de "imprevisibilidad" es fundamental y remite a la idea de un sistema dinámico y complejo, altamente incierto, en el cuál los luchadores intentan obtener indicios que constriñan el abanico de posibilidades $\mathrm{y}$, al mismo tiempo, intentan evitar ofrecer dichos indicios al adversario. Algunos trabajos (Davids, et al., 2006; Hristovski, et al., 2006; Hristovski, et al., 2011) señalan cómo las acciones ajustadas emergen en un escenario de constricciones y como en cierta medida dicho proceso es imprevisible. Desde nuestra perspectiva, además de los elementos contextuales que generan las acciones, éstas deben entenderse en un contexto guiado por las "intenciones tácticas". En los puntos siguientes, analizaremos con detalle cada una de estas dimensiones.

\section{Dimensión técnica del "saber luchar" - Situaciones características del combate}

Figueiredo (1998) conceptualizó las formas de finalización posibles, esenciales y específicas de las AM\&DC, como situaciones características del combate asumiéndose también como distintivas de las orientaciones técnicas de las diferentes modalidades y disciplinas constituyentes de este grupo de prácticas. Estas situaciones características del combate consideran los gestos técnicos observables como formas de finalización puntuable de la lucha en las diversas disciplinas de las AM\&DC. Dichos gestos técnicos son los "toques/golpeos", las "proyecciones", las "inmovilizaciones", las "estrangulaciones" y las "luxaciones".

La idea actual de las situaciones características del combate va más allá de la concreción de las acciones de finalización, las cuales representan el resultado de la intencionalidad ofensiva. Integra también las denominadas acciones neutralizadoras de la transición/finalización (gestos técnicos aplicados con intencionalidad defensiva que hacen inviables las acciones ofensivas y/o su preparación intencional en el proceso transitorio), y la discriminación de las acciones de transición (no puntuables) que permiten y preceden la ejecución de ambos procesos (hacia la finalización/neutralización). Esta organización de las situaciones características del combate se expone en los Cuadros 1 y 2.

Estas dos categorías de la acción técnica se relacionan con un grupo más amplio de acciones designadas como de transición. Éstas representan los gestos asociados a la dinámica y a las variaciones de la acción transitiva y potencian igualmente la intervención técnica ofensiva y defensiva de los contrincantes (a través de las dos categorías de acciones identificadas). Desde nuestro punto de vista, este grupo está constituido por las acciones presentadas en el Cuadro 2. Cabe destacar que estas acciones de transición, vinculadas a la dinámica de la guardia manifiestan, en su esencia, un considerable grado de dependencia y de articulación, presentándose en variadas circunstancias de forma simultánea.

En línea con lo expuesto, revisamos el concepto de situaciones características del combate anteriormente propuesto por Figueiredo (1998), reconociéndolas no solamente como las acciones representativas del combate debido al carácter definidor de su tipología, sino como un abanico que integra las posibilidades ofensivas y defensivas que constituyen el campo técnico de las AM\&DC.

\footnotetext{
${ }^{8}$ Uno de los principios condicionales de las luchas propuesto por Gomes, et al. (2010). Para los autores, este principio representa que "no existen estrategias secuenciales completamente previsibles en una lucha, ya que las acciones de un luchador pueden o no ser respuestas a las acciones del adversario, una vez que las estrategias de acción, anteriores a la realización de la técnica, también pueden ser simultáneas” (Gomes, et al., 2010, p. 214).
} 
Esta forma de considerar a las situaciones características del combate expresa, a través de las acciones de transición subyacentes a la guardia, la faceta táctica de la dimensión técnica del "saber luchar" (Cuadro 3).

Acciones de finalización (intencionalidad ofensiva)

Golpeos/Toques: acciones de impacto (real o potencial) realizadas con las superficies de las extremidades, con partes de los segmentos corporales o mediante la utilización de un arma a determinadas partes/áreas del cuerpo adversario. La dirección de la trayectoria determina su tipología (directa o circular). Se pueden diferenciar según la intensidad del contacto (desde el toque no lesivo hasta el impacto lesionador o la presión en puntos frágiles) y las dianas (puntos determinados más bien vinculados a la defensa personal o áreas consideradas puntuables de acuerdo con los reglamentos competitivos asumidos en las diferentes modalidades deportivas de combate).

Proyecciones: acciones realizadas por uno de los oponentes que hacen que su contrincante pierda el contacto con el suelo hacia fuera del área de actividad (trayectoria horizontal) o hacia el suelo (trayectoria vertical). Las proyecciones incluyen lo que normalmente se denomina como 'derribos' (acción que implica una trayectoria vertical donde el oponente no pierde totalmente el contacto con el suelo) y como 'barridos/rastreras' (acción de contacto realizado solamente con los segmentos inferiores y que implica la caída del oponente). La ejecución de estas acciones supone una distancia mínima y un contacto corporal elevado (con recurso del agarre) entre los oponentes, pudiendo ser realizadas a través de la utilización de 'palancas' o de 'binomio de fuerzas' (e.g., utilización de fuerzas contrarias: pies empujan y brazos tiran). Para poder ejecutar las proyecciones es necesaria la aplicación previa de un 'desequilibrio' al oponente de forma que potencie y facilite su ejecución.

Inmovilizaciones: el objetivo de estas acciones es el mantenimiento del adversario inmóvil, sin poder moverse o levantarse. Se pueden utilizar diferentes estrategias relacionadas con las áreas de incidencia, los apoyos utilizados, la utilización del peso del cuerpo o la superficie de contacto entre los cuerpos y el entorno.

Luxaciones/Llaves: buscan la inmovilización articular y el abandono del oponente a través del control y la presión en las articulaciones de los segmentos en el límite de sus grados de libertad.

Estrangulaciones: acciones aplicadas sobre el cuello del oponente, buscando su inmovilización y abandono a través de la acción de control y compresión de la garganta potenciando la asfixia mediante una constricción activa.

Acciones neutralizadoras de la transición/finalización (intencionalidad defensiva).

Bloqueo: interrupción brusca de la trayectoria de la acción ofensiva adversaria.

Desviación: alteración de la trayectoria de la acción ofensiva adversaria.

Esquiva: salida de la trayectoria de la acción ofensiva adversaria.

Cuadro 1. Acciones ofensivas y defensivas (fuente: elaboración propia).

Acciones de transición (doble intencionalidad)

Agarre: acciones de prensión realizadas fundamentalmente con las manos y segmentos superiores, pero también con los pies y segmentos inferiores de forma que ayudan a preparar otras acciones de transición y/o finalización y/o neutralizar las del adversario.

Contacto: acciones de control ejercidas a través de los impactos, impulsos o presiones efectuadas sobre el oponente (peso del cuerpo y/o fijación de los segmentos superiores/inferiores en áreas localizadas) y cuya intervención bajo la forma de impulso deberá potenciar la realización del toque/golpeo. El ejercicio de fijación promueve las acciones de proyección/inmovilización/luxación/estrangulación del oponente, así como, en ambas, la seguridad del oponente.

Desequilibrio: acciones que buscan la inestabilidad del otro de forma que la acción técnica de finalización tenga una mayor probabilidad de éxito. Ocurre a través de situaciones de tirar/empujar con agarre (en la distancia corta) o de toques circunstanciales (en las distancias corta/media/larga).

Desplazamiento: acciones de gestión de la distancia entre los oponentes basándose en la dinámica de los apoyos en el suelo con el objetivo de aproximación/alejamiento (multidireccional) y posicionamiento (facilitador de la ejecución) respecto al oponente y cuya dimensión espacial de medida (larga, media, corta) determina el tipo de acción finalizadora a realizar (golpeo, proyección o inmovilización/luxación /estrangulamiento), así como la respectiva acción defensiva (bloqueo/desviación/esquiva).

Cuadro 2. Acciones de transición (fuente: elaboración propia). 
Acciones de transición

\begin{tabular}{c|c} 
Acciones de finalización & $\begin{array}{c}\text { Acciones neutralizadoras de la } \\
\text { transición/finalización }\end{array}$ \\
\hline Intencionalidad ofensiva & Intencionalidad defensiva \\
\hline
\end{tabular}

Cuadro 3. Constituyentes de la dimensión técnica del "saber luchar" - Situaciones características del combate (fuente: elaboración propia).

De esta manera, las acciones de transición (agarre, contacto, desequilibrio y desplazamiento) sustentan y potencian la realización de las acciones de finalización (toques/golpeos, proyecciones, inmovilizaciones, luxaciones y estrangulaciones) y las eventuales acciones neutralizadoras de la transición/finalización resultantes (por bloqueo, desviación o esquiva). Las situaciones características del combate comparten significado con lo que Nascimento (2014, p. 181) designa como "elementos de las luchas"9 que se manifiestan a través de la posibilidad de cada oponente de "crear acciones de oposición intermediarias entre los fines de la lucha y las 'operaciones corporales' que pueden satisfacer tales fines".

\section{Dimensión táctica del "saber luchar" - Elementos de gestión}

Una vez observadas las acciones constituyentes de la dimensión técnica del "saber luchar", resulta necesario analizar los elementos constituyentes de la dimensión táctica, que en íntima relación con la anterior establecen los contenidos de este conocimiento particular de las AM\&DC. Para tal, partimos de considerar la acción táctica como el uso inteligente de las acciones motrices en combate (e.g., López-Ros, 2014). Esta noción es coincidente con la que se emplea en el análisis de los comportamientos deportivos en los JDC e implica, en nuestro caso, un proceso de toma de decisiones que está sujeto, por lo menos, a las intenciones tácticas y estratégicas, a las posibilidades propias y del adversario, y al desarrollo de la situación de combate.

Para la determinación de los elementos constituyentes de la dimensión táctica, nos basamos en el trabajo de Tokitsu (1979). Este autor, preocupado por el análisis de las diferentes dimensiones de la acción técnica asociadas a la perspectiva del Kárate Goshin-Do, diferencia el estado de aprendizaje de las técnicas del estado de utilización de dichas técnicas, estableciendo así dos perspectivas de observación asociadas. Una más vinculada a los patrones de ejecución y otra relacionada con los aspectos circunstanciales que influyen en ésta y cuyo significado le acerca a la noción que tenemos de táctica. Es en el ámbito de esta última perspectiva que Tokitsu (1979, p. 65) identifica las dimensiones de ma-ai ${ }^{10}$ (distancia), hyoshi11 (cadencia y ritmo) y yomi ${ }^{12}$ (percepción), las cuales, desde nuestro punto de vista, representan los elementos de gestión táctica.

Según Figueiredo (1998), la aportación de Tokitsu en la estipulación de estos elementos, se revela fundamental al señalar el reconocimiento y entendimiento de la acción táctica como factor de influencia en el desempeño del practicante de AM\&DC. Asimismo, a través de su planteamiento, se hace posible concebir la ejecución técnica, no solamente como un gesto aislado y mecanicista, sino también como una acción implicada y relacionada con el contexto circunstancial del practicante, su oponente y con la interacción establecida por ambos. No en vano, desde nuestra perspectiva el único gesto técnico válido en situación de combate es el que se muestra eficaz en la consecución del objetivo, y no aquel que se muestra solo preciso y perfecto en la dimensión mecánica de la ejecución.

\footnotetext{
${ }^{9}$ Nascimento (2014) identifica cuatro elementos de las situaciones de lucha que deben ser controlados por los jugadores: la base de apoyo, el ritmo de la lucha, la distancia de guardia y las formas de contacto.

${ }^{10}$ Significa el movimiento de aproximación y alejamiento entre dos personas y/o objetos.

${ }^{11}$ Significa el movimiento en relación a uno mismo y en relación al oponente.

12 Significa el arte de adivinar y de prever el oponente. No limitándose a decodificar una expresión concreta, comprende igualmente el arte de adivinar y prever ideas, los pensamientos y los sentimientos, las voluntades y los deseos. De este modo, yomi representa la actitud perceptivo-actuante de uno que, no solamente detecta la realidad permitiendo anticiparla, como también estimula su desencadenamiento.
} 
De esta forma, para que la técnica pueda ser ejecutada adecuadamente, el practicante necesita percibir la distancia y su cadencia, propia y con respecto al otro, es decir, tiene que efectuar una adecuada gestión del movimiento - a través del manejo de la "distancia de guardia"13, la cual consiste en la "distancia de enfrentamiento motor que separa a los dos adversarios de un duelo ludodeportivo en el momento inmediatamente anterior a la acción de ataque de uno de ellos" (Parlebas, 2001, p. 152). Al respecto, Lima (1995, p. II) señala que:

la noción de distancia se inserta en la capacidad de adaptación espacial del organismo al entorno; es función de las características de los desplazamientos (directamente dependientes de la noción de cuerpo y, por tanto, del sentido kinestésico utilizado por el combatiente) y del cálculo de las distancias.

El control de la distancia de guardia integra también la búsqueda intencional de la variabilidad en esa distancia como forma de determinar los ritmos de la lucha (Nascimento, 2014). Desde nuestro punto de vista, son esta noción dinámica de la distancia y la gestión que hacen los dos oponente en permanente movimiento las que determinan el desarrollo y la tipología de la interacción dual. Esto implica diferentes tipos de acción motriz de acuerdo con la distancia (corta, media o larga) a la que se encuentran los contrincantes ${ }^{14}$ (Avelar \& Figueiredo, 2009).

A su vez, el ritmo (la dimensión temporal) permite mantener o romper el equilibrio propio y de la esfera dialéctica del combate, además de determinar la calidad y encadenamiento de diferentes estructuras coordinativas de carácter técnico. Los cambios de ritmo implican alteraciones en el comportamiento de los contrincantes, estimulando su vulnerabilidad, así como rupturas en la distancia mantenida con respecto al otro (en aproximación o alejamiento). En palabras de Figueiredo (2000, s/p),

cuando los ritmos o cadencias son concordantes, no hay iniciativa explícita que fructifique en un ataque eficaz, ya que los movimientos de los protagonistas se completan y evitan, tal como si estuvieran parados. Solo cuando uno toma la iniciativa de crear un ritmo discordante, es cuando, al generarse 'desarmonía', se hace posible el juego, la victoria y la derrota.

Tal como queda indicado, la distancia y el ritmo van asociados porque entre ambos conceptos se revela una relación de reciprocidad, ya que la manipulación del ritmo, por ejemplo en los desplazamientos, permite manejar tácticamente la distancia con vistas a la realización o neutralización de las acciones propias o del contrincante. Por otro lado, el mantenimiento o variación de una determinada distancia, a través de la ocupación diferenciada del espacio disponible, permite romper la dinámica rítmica del oponente.

En otro nivel de relación, la percepción se asume como el elemento mediador y facilitador de los procesos anteriores. Cada oponente percibe en el otro sus dianas corporales, manifestadas en distancias y ritmos determinados, y es bajo esta toma de información que decide y realiza las acciones correspondientes a la situación observada (Figura 3). De esta manera, la toma de conciencia de la dinámica luctatoria, desarrollada a través de la percepción de las distancias y respectivas acciones asociadas, permite al practicante decidir qué ritmo y qué rol deberá aplicar

\footnotetext{
13 De acuerdo con Parlebas (2001) existen cuatro medidas de distancia de guardia: casi-nula, pequeña, media y grande. Basándose en estas medidas de distancia, Avelar y Figueiredo (2009) destacan los tipos de interacción y respectivas acciones motrices considerando las diferentes distancias de enfrentamiento (corta distancia: acciones de golpeo y agarre; media distancia: acciones de golpeo con las extremidades; larga distancia: acciones de golpeo con implemento). La “distancia grande” señalada por Parlebas (2001) no es considerada en el planteamiento de Avelar y Figueiredo (2009) porque esta hace referencia a las prácticas de oposición dual con utilización de raquetas (por ello las interacciones establecidas se dan en el espacio lejano).

${ }^{14}$ La corta, media o larga distancia implican diferentes tipos de interacción técnica y, en muchos casos, representan la asunción de determinadas normas particulares visibles en la manifestación de estas distancias, hecho que es coherente con Parlebas (1988, p. 136) al señalar que "determinada por las reglas, esta distancia [de enfrentamiento motor] caracteriza cada tipo de confrontación”. Por otro lado, esas diferentes distancias sobresalen como referentes espaciales que determinan la especificidad de las diferentes situaciones en las modalidades institucionalizadas de combate, las cuales se organizan de acuerdo con los designados "grupos situacionales” (Gomes, et al., 2010) donde el factor "distancia" se asume como referente taxonómico.
} 
(Figueiredo, 1998). El significado asociado a este elemento de gestión táctica remite también a los aspectos relacionados con la toma de iniciativa por parte de cualquiera de los oponentes, a través de la realización intencional de acciones de ataque, de anticipación o de contraataque.

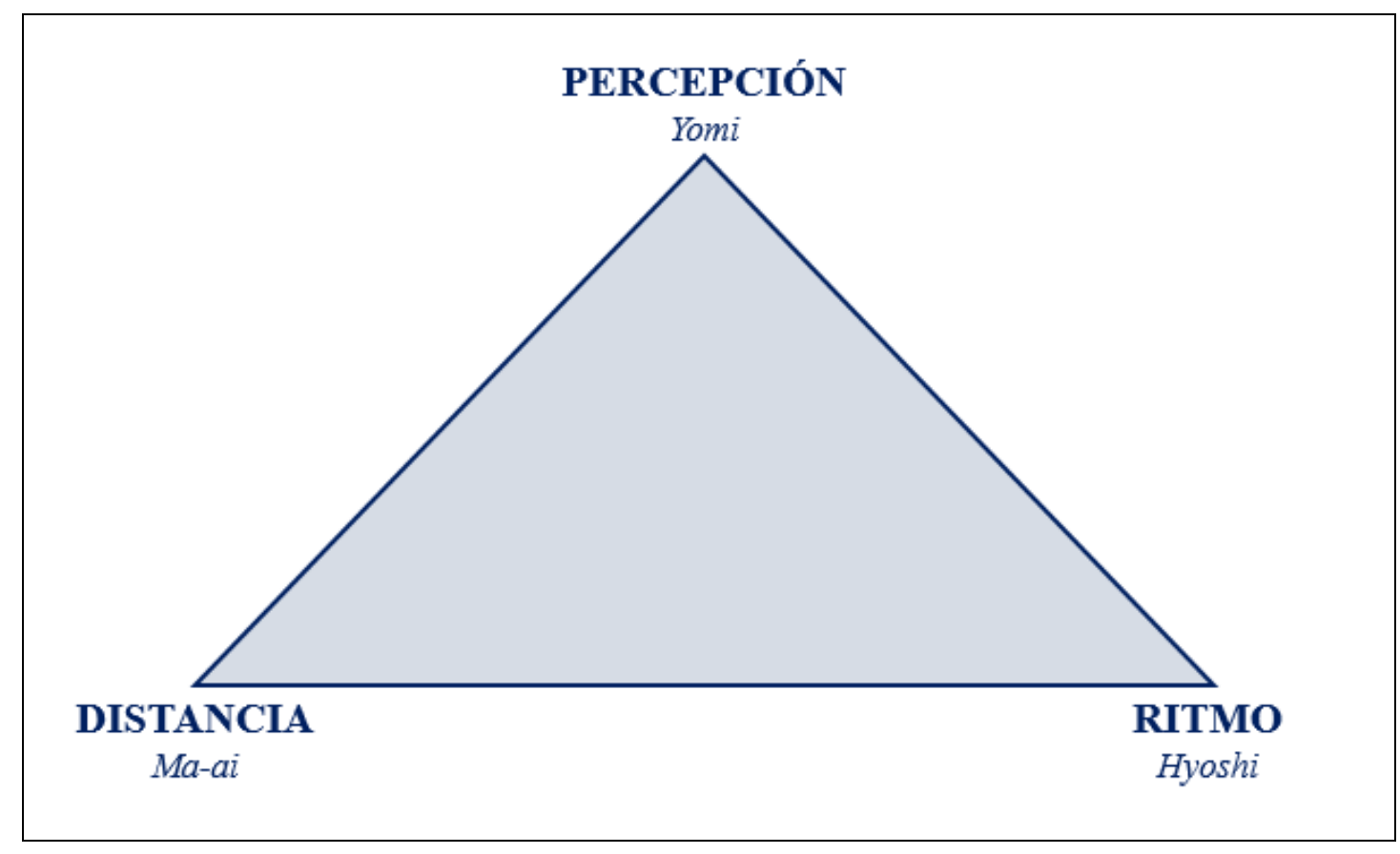

Figura 3. "Elementos de gestión táctica” (basado en Tokitsu, 1979; Figueiredo, 1998, p. III).

En esta línea, la dialéctica del combate implica la gestión del equilibrio espacial y rítmico propio y respecto al otro, buscando la sincronización (asociada a acciones con intención táctica más defensiva) o la ruptura de ese equilibrio (asociado a acciones con intención táctica más ofensiva). Asimismo, se establece una relación polarizada entre "estabilizar" y "romper" que, desde el punto de vista táctico, se manifiesta en la dinámica luctatoria de ambos oponentes, particularmente a través de la acción intencional de la guardia.

La intencionalidad de la acción ofensiva por uno o ambos contrincantes nos lleva también a otra problemática asociada a la gestión táctica de la dialéctica luctatoria y que se relaciona con la toma de iniciativa. Es la designada como sen en el ámbito de las artes marciales japonesas. La doble reciprocidad de la acción de los oponentes añade importancia a la iniciativa de uno de ellos sobre el otro, considerando las posibles consecuencias exitosas o fracasadas de ésta.

Para Lowry (2002, p. 114) sen significa "específicamente aquel momento decisivo cuando la acción es iniciada". Se consideran dos tipos principales de sen, el go no sen que está asociado a la contrainiciativa, y el sen no sen que está asociado a la anticipación de la acción del otro. Al respecto, Lowry (2002) observa que este análisis de la iniciativa podría indicar que la anticipación revela un estado avanzado de dominio de la dinámica luctatoria, ya que el contrincante que anticipa las acciones tendría ventaja frente al otro. Sin embargo, el go no sen, que a menudo es interpretado como una actitud más pasiva por ser de espera, puede representar también la capacidad táctica de, intencionadamente, provocar en el otro la acción que le permita a uno efectuar un contraataque eficaz.

Esta perspectiva de la iniciativa y de la contrainiciativa desvela la existencia de diferentes estrategias que podrán ser concretadas por los luchadores para la obtención del éxito. Si por un lado, la estrategia podrá incidir en el intento de lograr la anticipación de las acciones del otro (el sen no sen), por otro lado, podremos considerar la posibilidad de provocar la acción del otro, para luego contraatacar, beneficiándonos, tal como sugiere Terrisse (1991) de la abertura concedida por el ataque adversario (el go no sen). 
Al respecto de la asunción de diferentes estrategias por parte de los luchadores, Oliva, Torres, y Navarro (2002, p. 279), en la línea de lo que llaman "factor SMP"15 ("sentimientomovimiento-pensamiento"), describen los bloques de luchadores, es decir, "la clasificación primera en la forma de afrontar el combate, sea éste reglado o no". Para los autores, "dependiendo de cuál sea la dominancia de un elemento [S, M o P] constituyente sobre los demás se establecen los bloques" (Oliva, Torres, \& Navarro, 2002, p. 279), los cuales son representados de la siguiente manera.

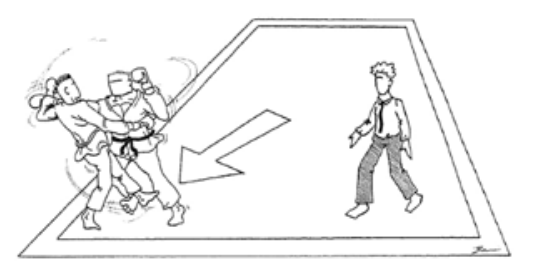

Bloque Motórico

"El combatiente que resuelve los combates basándose en la supremacía del gesto y de las facultades físicas por encima de todo."

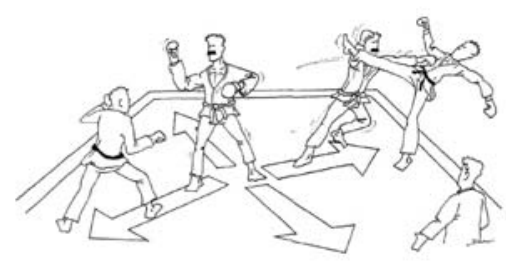

Bloque Racional

"El combatiente que resuelve sus combates con predominio de la lógica y bajo el concurso de una lucha cómoda y segura."

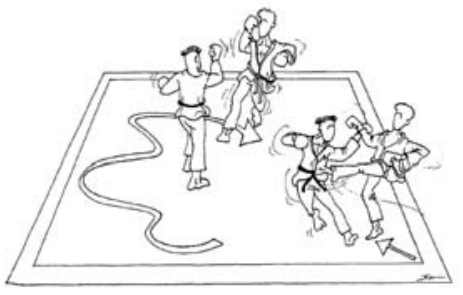

Bloque Pasional

"El combatiente que resuelve sus combates de forma instintiva, explosiva y muchas veces escandalosa, en el que domina el sentimiento y el instinto."

Cuadro 4. Bloques del “factor SMP” (Oliva, Torres, \& Navarro, 2002, p. 279).

Estos bloques categorizan las diferentes formas de luchar demostrando, a la vez, las tendencias estratégicas que podemos encontrar en el combate. Sin embargo, más allá de esta sistematización con interés particular para el ámbito del rendimiento deportivo, las características asociadas a cada uno de los bloques nos parecen importantes. Éstos podrían asumirse como criterio en tareas con predominancia táctica, ya que el dominio de un bloque sobre el otro implica la asunción de diferentes formas de tomar y gestionar la iniciativa. El dominio del comportamiento asociado a cada bloque, y su capacidad de variación en función de la circunstancia, podrá representar la manifestación de la "intención táctica" por parte del luchador, ya que demuestra intencionalmente la iniciativa de cambiar los ritmos y de gestionar las distancias de acuerdo con su percepción de la dinámica luctatoria.

En este sentido, tal como se ha señalado por los autores del concepto de "saber luchar" (Terrisse, 1991, 1996; Terrisse, et al., 1995) y como hemos indicado anteriormente, su dominio se evidencia a través de la demostración de una "intención táctica" cuya manifestación disminuye la imprevisibilidad típica de las situaciones de oposición dual. En su dimensión funcional, esta intencionalidad, permite al practicante desarrollar, buscar e instrumentalizar la mejor respuesta técnica a la circunstancia de combate en la que se encuentra, así como gestionar y manipular los elementos tácticos mencionados. Efectivamente, tal como destaca Nascimento (2014, p. 181):

la intencionalidad en la búsqueda de las acciones corporales que satisfacen los objetivos de la lucha para el ataque y la defensa se constituye como la primera forma consciente de actuar en las relaciones esenciales y necesarias presentes en el control de la acción corporal del otro en la actividad de lucha. Se trata de un primer momento del proceso de creación de acciones corporales para el control del cuerpo del otro y del propio cuerpo.

\footnotetext{
${ }^{15}$ El factor SMP, donde S (sentimiento), M (movimiento) y P (pensamiento), en relación, representan el triángulo base del análisis de estos autores a través de la asunción de que "el movimiento (M) en su acción daba vida a la técnica, el pensamiento $(\mathrm{P})$ en sus planteamientos conformaba la táctica que, paralelamente, el sentimiento (S), a través de pulsiones, daba pie a la emótica” (Oliva, Torres, \& Navarro, 2002, p. 276). Sin embargo, la posición de cada factor en el triángulo no está previamente determinada, ya que "la gran disparidad de formas y maneras de interpretar el Arte del Combate hoy en el mundo, dentro de los denominados deportes de oposición, combate o lucha, debe su origen a la infinidad de posibilidades de expresión, manifestación y vida de 'S', 'M' y 'P'” (Oliva, Torres, \& Navarro, 2002, p. 278).
} 
Es en esta lógica que Gomes, et al. (2010, p. 213) afirman que "pensar la lucha es tan importante como realizar la acción de lucha".

Desde nuestro punto de vista, es posible asociar esta intencionalidad táctica a la noción de pensamiento operativo, el cual "permite a los deportistas manejar mayores cantidades de información y actuar más acertadamente, discriminando de forma más certera la información relevante y anticipando los escenarios posibles de actuación; y, fundamentalmente tener un comportamiento eficaz que permita resolver el problema al que se enfrentan" (López-Ros, 2011a, p. 61). Este planteamiento prospectivo de la táctica, también se ha conceptualizado como "pensamiento táctico"16, el cual se define como:

un tipo de pensamiento operativo, que se muestra en la práctica, formado por un conocimiento técnico-táctico que incluye diferentes tipos de saberes, que en expertos se manifiesta como de alta calidad, y que permite guiar el comportamiento táctico en la resolución de los problemas deportivos específicos. (López-Ros, 2011b, p. 78)

De esta manera, la acción intencional del practicante es funcional (orientada hacia el objetivo), interactiva (con respecto al otro) y eficiente (por la gestión de recursos propios y ajenos) manifestándose, no por la "emergencia casual" de respuestas aisladas, sino por la percepción y conocimiento de la dialéctica luctatoria.

Asimismo, el conocimiento de diferentes posibilidades de acción deberá implicar la reducción de la incertidumbre del practicante y el fortalecimiento de su "intención táctica". Por otro lado, la acción táctica consiste también en provocar un fallo en el sistema defensivo del otro a través, por ejemplo, de acciones de disuasión (fintas y simulaciones; exploración y manipulación de la acción del otro a través de su distracción o provocándole una reacción) vinculadas a las acciones de transición, asumiendo además que esa intención es recíproca (Terrisse, 1991). Para Nascimento (2014, p. 211):

es ahí donde reside la importancia y el papel de la enseñanza de conocimientos estratégicotácticos en el proceso de enseñanza de los juegos y de las luchas: ellos son mediadores de las acciones de los jugadores, contribuyendo a que sus relaciones con la percepción, evaluación y solución del juego dejen de ser directas (dadas por aquello que les es inmediatamente percibido), y pasen a ser mediadas por un conjunto de conocimientos y principios de juego (un conjunto de modos generales de acción) que les permite 'ver' en el juego o en la lucha aquello que puede suceder.

La "intención táctica" en AM\&DC implica pues la capacidad de manejar de forma eficiente el espacio y las interacciones con el oponente (a través de la manipulación de la distancia y del ritmo, pero también de la iniciativa), y se manifiesta en la utilización de las acciones de transición con el propósito de realizar una acción de finalización en el momento adecuado. La calidad de las percepciones obtenidas a lo largo del proceso dialéctico determinará el éxito de las decisiones tomadas con vistas al logro del propósito mencionado.

De forma convergente, la demostración espontánea de la "intención táctica" puede estar asociada al concepto de flow (flujo/fluir) estudiado en el ámbito de las prácticas deportivas, el cual hace referencia a "capturar el estado de conciencia en el cual el atleta se 'pierde en el flujo' de la acción cuando es desafiado apropiadamente" (Light, 2014, p. 43). El significado de flow se acerca conceptualmente a la noción de mushin, un término vinculado a las artes marciales japonesas que "describe un estado alcanzado después de largos periodos de entrenamiento por los cuales se vuelve posible la acción pura a través de la unidad entre mente, cuerpo y espíritu como un todo y la eliminación de la interferencia de la conciencia" (Light, 2014, p. 32). De esta manera, la asociación

\footnotetext{
${ }^{16}$ De acuerdo con López-Ros (2011b, p. 77), “el pensamiento operativo al que aludimos ha sido definido por algunos trabajos como pensamiento táctico (Ripoll, 1987; Ruiz Pérez \& Arruza, 2005) y se ha asociado de forma estrecha con el 'conocimiento táctico' (Gréhaigne \& Godbout, 1995) y con la 'competencia táctica’, remitiéndonos en definitiva a un tipo de conocimiento práctico, un ‘conocimiento en acción’ (Gréhaigne, Richard, \& Griffin, 2005) que permite ser operativo y eficaz en la resolución de tareas deportivas con implicación táctica y, por tanto, con altos niveles de complejidad decisional e incertidumbre”.
} 
del concepto de mushin a la "intención táctica" podrá suponer también la muestra espontánea de una manifestación de alta calidad.

Según lo expuesto, la "intención táctica" representa la utilización contextualizada, intencional y espontánea de los recursos técnico-tácticos demostrando, no solamente el dominio del "saber luchar" tal como es destacado por Terrisse $(1991,1996)$ y Terrisse, et al. (1995), sino también la manifestación de este conocimiento con alto nivel práxico y dialéctico, características comunes entre los practicantes expertos (Castejón, 2003, 2010). Por este motivo, la "intención táctica", y la respectiva reducción de la incertidumbre asociada a las diferentes formas de tomar la iniciativa, se asumen también como los objetivos del proceso de enseñanza-aprendizaje en el ámbito de la iniciación a las AM\&DC (Terrisse, et al., 1995).

A partir de la articulación entre los elementos constituyentes de las dimensiones técnica y táctica presentados resulta la creación de la "estructura técnico-táctica del saber luchar" (Figura 4). Esta estructura pretende caracterizar transversalmente los contenidos a desarrollar en un proceso de enseñanza-aprendizaje en AM\&DC, independientemente de la orientación de sus disciplinas, considerando el propósito de la "intención táctica" como el objetivo prioritario y fundamental del proceso de enseñanza-aprendizaje del "saber luchar".

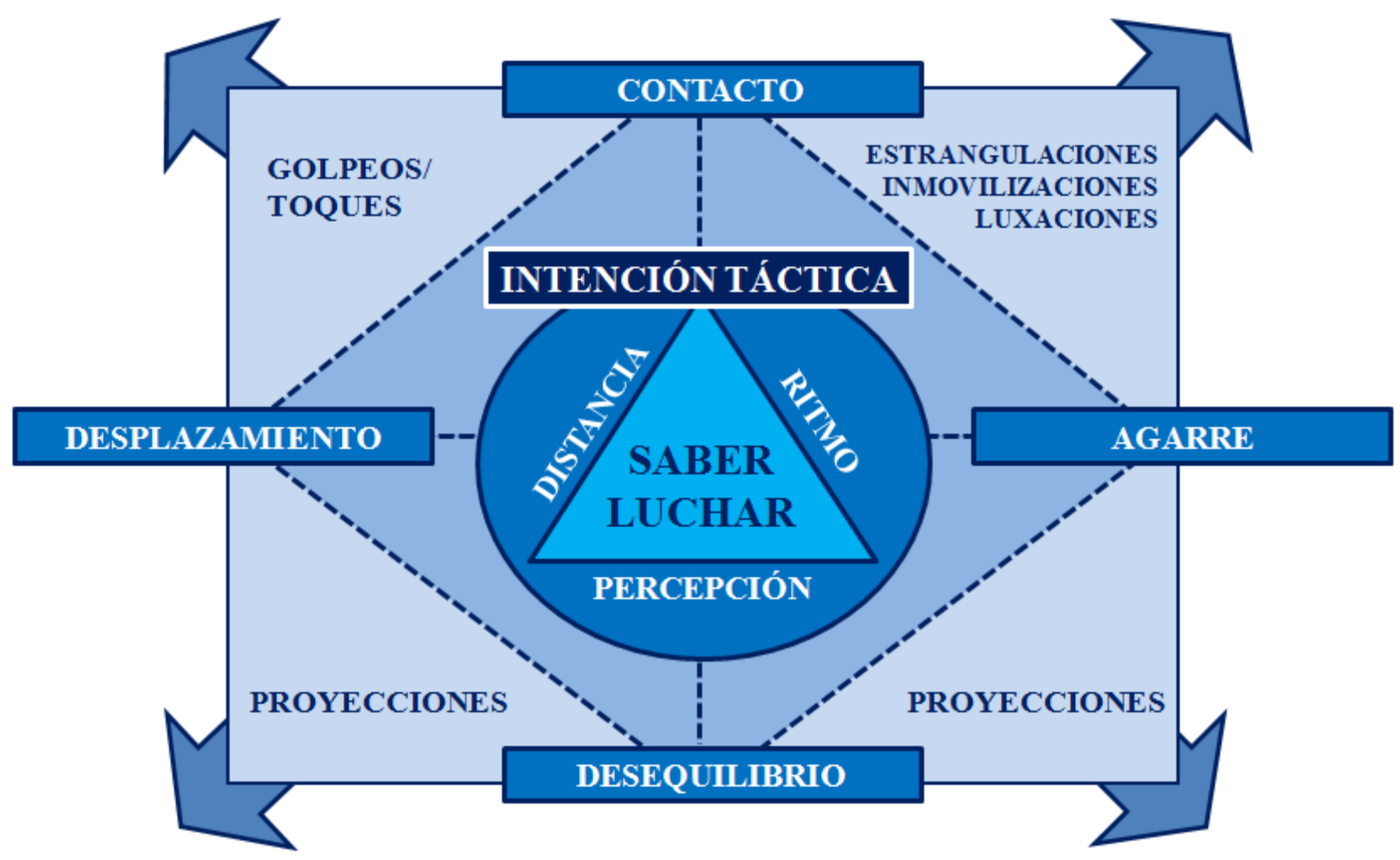

Figura 4. "Estructura técnico-táctica del saber luchar" (fuente: elaboración propia).

De este modo, y de acuerdo con la estructura presentada, representamos el "saber luchar" como el dominio y relación de las acciones de transición, determinantes de las acciones de finalización ${ }^{17}$, en articulación con los elementos de gestión táctica. En consonancia con el desarrollo e intensidad de esta interrelación se construye la "intención táctica", manifestación de un "saber luchar" de calidad.

\footnotetext{
17 Debido al reconocimiento de las acciones con intencionalidad ofensiva como aquellas que representan la iniciativa puntuada del combate (la pasividad no es valorada desde el punto de vista luctatorio, así como, en la misma línea, la intencionalidad defensiva tampoco es puntuable), consideramos las "situaciones características del combate” vinculadas a la intencionalidad defensiva como no determinantes de la acción luctatoria, una vez que, en su estructura y esencia, son resultado, consecuencia y precaución de la iniciativa del oponente. Por esta razón, las acciones con intencionalidad defensiva no salen esquematizadas en la estructura propuesta, tal como tampoco han sido integradas en la dinámica matriz de combate expresada en la Figura 2.
} 


\section{Conclusión}

A través del planteamiento presentado mostramos nuestra intención de identificar y sistematizar los contenidos técnicos y tácticos esenciales, transversales y caracterizadores de las AM\&DC, con vista a una interpretación integrada y global de estas prácticas. Asimismo, buscamos acercarnos a la respuesta de la cuestión sobre “¿qué enseñar?" en las AM\&DC planteada por Nascimento y Almeida (2007) en su análisis a la pedagogía de las luchas, considerando de esta manera "cuáles serían las situaciones fundamentales (y al mismo tiempo generales) para que sean percibidas, analizadas y planificadas en acciones en las actividades de juego y lucha" (Nascimento, 2014, p. 185).

Partiendo de la discusión acerca de la lógica interna particular de las AM\&DC, se ha propuesto la observación de estas prácticas a partir de las posibilidades que confiere la guardia, la cual sostiene y promueve el desarrollo de las diferentes acciones asociadas a los procesos de transición y de finalización, representando también la simultaneidad de los procesos ofensivos y defensivos. De acuerdo con su doble funcionalidad, la guardia estimula, a la vez, el desarrollo de las situaciones características del combate (potenciando la realización de las acciones de transición y las acciones de finalización o las acciones de neutralización en contra de las anteriores), y la manipulación de los elementos que permiten gestionar el proceso táctico y la toma de iniciativa que va asociada. La construcción de la "intención táctica", considerada por sus autores (Terrise, 1991, 1996; Terrisse, et al., 1995) como la manifestación de un "saber luchar" de alta calidad, será el resultado de un proceso de articulación entre las dimensiones técnica y táctica cuyos elementos aparecen destacados en la "estructura técnico-táctica del saber luchar" presentada. Esta estructura debería permitir la interpretación de la praxis luctatoria a través del enfoque en los conocimientos que confieren identidad a las AM\&DC entendidas en su sentido global.

Más allá de su esencia globalizadora, esta estructura permite también una interpretación más vinculada al ámbito específico de las diferentes modalidades que constituyen este grupo de prácticas. Ello hará posible promover, por un lado, el desarrollo de un "saber tocar", "saber proyectar", "saber inmovilizar", "saber estrangular" o "saber luxar" en un planteamiento con carácter celular o, por otro lado, el "saber Kárate" o "saber Judo" (o cualquier otra disciplina específica), considerándolos como el conjunto y organización de los "saberes" de la "estructura técnico-táctica del saber luchar" que predominan en estas prácticas. De esta manera, el "saber luchar" integra el conjunto de conocimientos que caracterizan las diferentes disciplinas de las AM\&DC y, a la vez, representa la manifestación de sus principios comunes.

Más allá de los principios y contenidos constituyentes del "saber luchar", queda todavía por aclarar la orientación didáctica asociada a este planteamiento, de forma que se puedan establecer los procesos asociados al proceso pedagógico de iniciación a las AM\&DC. Este aspecto, dada su dimensión, será objeto de posteriores trabajos.

\section{Agradecimientos}

Los autores desean expresar su agradecimiento a los revisores anónimos por las aportaciones realizadas y a Roberto Sánchez Gómez por su colaboración en la revisión del manuscrito.

\section{Referencias}

Amador, F. (1997). El Análisis de la Acción de Lucha. En VV. AA. El Judo y las Ciencias de la Educación Física y el Deporte (pp. 51-70). Vitoria-Gasteiz: Instituto Vasco de Educación Física.

Avelar, B., \& Figueiredo, A. (2009). La iniciación a los deportes de combate: interpretación de la estructura del fenómeno lúdico luctatorio. Revista de Artes Marciales Asiáticas, 4(3), 44-57.

Bayer, C. (1986). La Enseñanza de los Juegos Deportivos Colectivos. Barcelona: Hispano-Europea.

Castarlenas, J. (1993). Estudio de las situaciones de oposición y competición. Aplicación de los Universales Ludomotores a los deportes de combate. Apunts: Educación Física y Deportes, 32, 54-64. 
Castejón, F.J. (2003). A vueltas con los expertos y los novatos en el deporte: lo que no hacen, lo que pueden hacer y lo que hacen. En F.J. Castejón (Coord.). Iniciación Deportiva - La Enseñanza y el Aprendizaje Comprensivo en el Deporte (pp. 87-110). Sevilla: Wanceulen.

Castejón, F.J. (2010). La toma de decisiones en expertos y noveles: diferencias y consideraciones prácticas. En V. López-Ros \& J. Sargatal (Eds.). La Táctica Deportiva y la Toma de Decisiones (pp. 69-88). Girona: Càtedra d'Esport i Educació Física de la Universitat de Girona.

Davids, K., Button, C., Araújo, D., Renshaw, I., \& Hristovski, R. (2006). Movement models from sports provide representative task constraints for studying adaptative behavior in human movement systems. Adaptative Behavior, 14(1), 73-95.

Devís, J., \& Sánchez, R. (1996). La enseñanza alternativa de los juegos deportivos: antecedentes, modelos actuales de iniciación y reflexiones finales. En J. A. Moreno \& P. L. Rodríguez (Comps.). Aprendizaje Deportivo (pp. 159-181). Murcia: Universidad de Murcia.

Espartero, J., Gutiérrez-García, C., \& Villamón, M. (2003). Las actividades de lucha. En B. Tabernero \& S. Márquez (Eds.). Educación Física: Propuestas para el cambio (pp. 283-324). Barcelona: Editorial Paidotribo.

Figueiredo, A. (1997). Os Desportos de Combate nos Programas de Educação Física. Horizonte, 80, 36-39.

Figueiredo, A. (1998). Os Desportos de Combate nas Aulas de Educação Física. Horizonte, 81, Dossier.

Figueiredo, A. (2000). Os Desportos de Combate nas Aulas de Educação Física. $8^{o}$ Congresso de Educação Física e Ciências do Desporto dos Países de Língua Portuguesa. 16-17 diciembre 2000. Lisboa: Faculdade de Motricidade Humana, Universidade Técnica de Lisboa. Disponible en <http://hdl.handle.net/10400.19/465>. Acceso el 13 agosto 2013.

Figueiredo, A. (2003). Os exercícios de treino do Karaté - Introdução à posição de base fundamental (guarda). Karate Portugal, 1(3), 17-18.

Figueiredo, A. (2006). A Institucionalização do Karaté - Os Modelos Organizacionais do Karaté em Portugal. Tesis de Doctorado (no publicada). Lisboa: Faculdade de Motricidade Humana, Universidade Técnica de Lisboa.

Gomes, M. (2014). O Ensino do Saber Lutar na Universidade: Estudo da Didática Clínica nas Lutas e Esportes de Combate. Tesis de Doctorado (no publicada). Campinas: Faculdade de Educação Física, Universidade Estadual de Campinas.

Gomes, M., Morato, M., Duarte, E., \& Almeida, J. (2010). Ensino das Lutas: dos princípios condicionais aos grupos situacionais. Movimento, 16(2), 207-227.

Gréhaigne, J.F., \& Godbout, P. (1995). Tactical knowledge in team sports from a constructivist and cognitivist perspective. Quest, 47, 490-505.

Gréhaigne, J.F., Richard, J.F., \& Griffin, L. (2005). Teaching and Learning Team Sports and Games. New York: Routledge Falmer.

Gutiérrez-García, C., \& Pérez Gutiérrez, M. (2009). Study on scientific production in martial arts in Spain from 1990 to present. En W. J. Cynarsky (Ed.), Martial Arts and Combat Sports Humanistic Outlook (pp. 90-115). Rzeszów: Wydawnictwo Uniwersytetu Rzeszowkiego.

Hernández Moreno, J. (1995). La diversidad de prácticas. Análisis de la estructura de los deportes para su aplicación a la iniciación deportiva. En D. Blázquez (Dir.): La Iniciación Deportiva y el Deporte Escolar (pp. 287-310). Barcelona: INDE.

Hristovski, R., Davids, K., Araújo, D., \& Button, C. (2006). How boxers decide to punch a target: emergent behaviour in nonlinear dynamical movement systems. Journal of Sports Science and Medicine, Combat Sports Special Issue 1, 60-73.

Hristovski, R., Davids, K., Araújo, D., \& Passos, P. (2011). Constraints-induced emergence of functional novelty in complex neurobiological systems: a basis for creativity in sports. Nonlinear Dynamics, Psychology, and Life Sciences, 15(2), 175-206.

Light, R. (2014). Mushin and learning in and beyond Budo. IDO - Movement for Culture - Journal of Martial Arts Anthropology, 14(3), 42-48.

Lima, A. (1995). As bases das actividades físico-desportivas dos desportos de combate. Horizonte, 66, Dossier.

Lima, A. (1997). Os Desportos de Combate (DC) como matéria de Educação Física (EF) nos Ensino Básico e Secundário. Horizonte, 86, 17-28. 
López-Ros, V. (2011a). Operaciones Cognitivas en la Iniciación Deportiva. El Pensamiento Táctico. Movimiento Humano, 1, 59-74.

López-Ros, V. (2011b). El Pensamiento Táctico y su desarrollo. En V. López-Ros \& J. Sargatal (Eds.). La Táctica Individual en los Deportes de Equipo (pp. 75-93). Girona: Càtedra d'Esport i Educació Física de la Universitat de Girona.

López-Ros, V. (2014). La acción táctica deportiva, Controversias y desafíos sobre su aprendizaje. En V. López-Ros \& J. Sargatal (Eds.). El Aprendizaje de la Acción Táctica (pp. 11-33). Girona: Càtedra d'Esport i Educació Física de la Universitat de Girona.

López-Ros, V., \& Castejón, F.J. (1998). Técnica, táctica individual y táctica colectiva: teoría de la implicación en el aprendizaje y la enseñanza deportiva (I). Revista de Educación Física, 68, 59.

Lowry, D. (2002). Traditions - Essays on the Japanese Martial Arts and Ways. Boston: Tuttle Publishing.

Nascimento, C. (2014). A Atividade Pedagógica da Educação Física - A proposição dos objetos de ensino e o desenvolvimento das atividades da cultura corporal. Tesis de Doctorado (no publicada). São Paulo: Faculdade de Educação, Universidade de São Paulo.

Nascimento, P., \& Almeida, L. (2007). A tematização das Lutas na Educação Física escolar: restrições e possibilidades. Movimento, 13(3), 91-110.

Oliva, A., Torres, F., \& Navarro, J. (2002). Combate Supremo. Madrid: CICAC.

Parlebas, P. (1988). Elementos de Sociología del Deporte. Málaga: Junta de Andalucía.

Parlebas, P. (2001). Juegos, Deporte y Sociedad. Léxico de Praxiología Motriz. Barcelona: Editorial Paidotribo.

Pérez-Gutiérrez, M. (2012). Repertorio Bibliográfico, Análisis Bibliométrico y Sociocultural de las Monografías sobre Artes Marciales Asiáticas publicadas en España. Tesis Doctoral (no publicada). León: Departamento de Educación Física y Deportiva, Universidad de León.

Pérez-Gutiérrez, M., Gutiérrez-García, C., \& Escobar-Molina, R. (2011). Terminological recommendations for improving the visibility of scientific literature on martial arts and combat sports. Archives of Budo, 7(3), 159-166. Disponible en $<$ http://www.archbudo.com/fulltxt.php?ICID=881910 $>$. Acceso el 04 septiembre 2011.

Ripoll, H. (1987). Stratégies de prise d'informations visuelles dans les tâches de resolution de problémes tactiques du sort. En H. Ripoll \& G. Azémar (Eds.). Neursociences du Sport (pp. 329354). Paris: INSEP.

Ruiz Pérez, L., \& Arruza, J. (2005). El Proceso de Toma de Decisiones en el Deporte - Clave de la Eficiencia y el Rendimiento Óptimo. Barcelona: Paidós.

Sánchez, R. (2009). ¿Qué significa pensar en acción? Apunts: Educación Física y Deportes, 98, 88-96.

Terrisse, A. (1991). Pour un enseignement dialectique des sports de combat. Revue EPS, 229, 23-26.

Terrisse, A. (1994). Para una enseñanza "dialéctica" de los deportes de combate. Revista de Educación Física, 59, 9-14.

Terrisse, A. (1996). Analyse de la transposition didactique du Judo: evolution du "savoir combattre" dans l'enseignement du Judo à l'école à travers la Revue EPS de 1950 a 1993. Revue Française de Pédagogie, 116, 65-76.

Terrisse, A., Quesada, Y., Sauvegrain, J., \& Hiegel, P. (1995). Le Savoir Combattre: Essai d'Élucidation. Revue EPS, 252, 26-29.

Tokitsu, K. (1979). La Voie du Karaté - Pour une Théorie des Arts Martiaux Japonais. Paris: Éditions du Seuil.

\section{Author's biographical data}

Bruno Avelar-Rosa es Licenciado en Ciencias del Deporte por la Faculdade de Motricidade Humana de la Universidade Técnica de Lisboa, postgraduado en Motricidad Infantil por el Institut Nacional d'Educació Física de Catalunya (Centro de Barcelona) y posee el Diploma de Estudios Avanzados en Educación Física y Deporte: Didáctica y Desarrollo Profesional, obtenido en la Facultat de Formació de Professorat de la Universitat de Barcelona. Actualmente está concluyendo su Tesis Doctoral en la Universitat de Girona, vinculada al tema de "La Construcción de Conocimiento en Iniciación a los Deportes de Combate - Organización de la Actividad 
Conjunta en el Desarrollo del 'Saber Luchar'". Es Profesor Asistente en la Escola Superior de Educação del Instituto Politécnico de Viseu. Es cinturón negro de Kárate y Judo, estando acreditado como entrenador de ambas modalidades, y, entre 2011 y 2014, ha sido Director del Departamento de Formación de la Federação Nacional de Karate - Portugal. E-mail: bruno.ibe@gmail.com.

Mariana Simões Pimentel Gomes es Diplomada y Licenciada en Educación Física por la Faculdade de Educação Física de la Universidade Estadual de Campinas. El 2007/2008 ha sido becaria del Programa Santander de Movilidad Internacional en el Instituto Nacional de Educación Física de la Universidade de A Coruña con tema subordinado a los "Procedimientos pedagógicos para la enseñanza de las luchas". Posee un Máster en Actividad Física, Adaptación y Salud en la Faculdade de Educação Física Física de la Universidade Estadual de Campinas, el cual fue obtenido tras la presentación de la disertación "Procedimentos Pedagógicos para o Ensino das Lutas: Contexto e Possibilidades". Es Doctora en Actividad Física Adaptada por la misma Facultad de su formación de grado y postgrado, habiendo realizado, en el ámbito de su proceso Doctoral, una estancia internacional en la Université de Toulouse II relacionada con el análisis de la Enseñanza en los Deportes de Combate en la Universidad, resultando de aquí su Tesis sobre "O Ensino do Saber Lutar na Universidade: Estudo da Didática Clínica nas Lutas e Esportes de Combate". Actualmente desarrolla proyectos de investigación relacionados con la enseñanza de los Deportes de Combate, Pedagogía del Deporte y Actividad Física y Deporte para Personas con Deficiencia. Es cinturón de negro de Jiu-Jitsu brasileño y practicante de Judo. E-mail: marianaspg@gmail.com.

Abel Figueiredo es Licenciado en Educación Física, rama de Deporte, por el Instituto Superior de Educação Física de la Universidade Técnica de Lisboa, posee un Máster en Ciencias de la Educación, en la Metodología de la Educación Física y es Doctorado en Motricidad Humana, en la especialidad de Ciencias del Deporte, ambos obtenidos en la Faculdade de Motricidade Humana de la Universidade Técnica de Lisboa. Es Profesor Adjunto en la Escola Superior de Educação del Instituto Politécnico de Viseu donde coordina la Licenciatura en Deporte y Actividad Física. Autor de diversos artículos académicos en diferentes ámbitos de las las AM\&DC (educación, ocio, salud, competición, institucionalización), es actualmente Vice-Presidente de la International Martial Arts and Combat Sports Scientific Society. Cinturón negro, 6o dan y entrenador de nivel IV de Kárate, es Presidente de la Associação Nacional de Treinadores de Karate y, desde hace 20 años, Asesor Técnico para la Formación de la Federação Nacional de Karate - Portugal. E-mail: abel.figueiredo@esev.ipv.pt.

Víctor López-Ros es Licenciado en Educación Física por el Institut Nacional d'Educació Física de Catalunya (Centro de Barcelona) y Doctor en Psicología por la Universitat de Girona. Es Profesor Titular de Universidad, en el Departamento de Didácticas Específicas de la Universitat de Girona. Es Director de la Cátedra de Deporte y Educación Física - Centro de Estudios Olímpicos de la Universitat de Girona, miembro del Grupo de Investigación "Cultura y Educación" y del Instituto de Investigación Educativa de la Universitat de Girona. Autor de diversos trabajos académicos en el ámbito del análisis del proceso de enseñanza-aprendizaje en Educación Física y deporte, particularmente vinculados a los modelos de enseñanza comprensiva del deporte y su planteamiento constructivista. E-mail: victor.lopez@udg.edu. 